\title{
A national FFQ for the Netherlands (the FFQ-NL 1.0): development and compatibility with existing Dutch FFQs
}

\author{
Simone JPM Eussen ${ }^{1, *}$, Martien CJM van Dongen ${ }^{2}$, Nicole EG Wijckmans ${ }^{1}$, \\ Saskia Meijboom ${ }^{3}$, Henny AM Brants ${ }^{4}$, Jeanne HM de Vries ${ }^{3}$, \\ H Bas Bueno-de-Mesquita ${ }^{4,5,6}$, Anouk Geelen ${ }^{3}$, Diewertje Sluik ${ }^{3}$, Edith JM Feskens ${ }^{3,} \dagger$, \\ Marga C Ocké ${ }^{4} \dagger$ and Pieter C Dagnelie ${ }^{1, \dagger}$ \\ 'Department of Epidemiology, CARIM School for Cardiovascular Diseases, Maastricht University, PO Box 616, \\ 6200 MD Maastricht, The Netherlands: ${ }^{2}$ Department of Epidemiology, CAPHRI School for Public Health and Primary \\ Care, Maastricht University, Maastricht, The Netherlands: ${ }^{3}$ Division of Human Nutrition, Wageningen \\ University, Wageningen, The Netherlands: ${ }^{4}$ National Institute for Public Health and the Environment, Bilthoven, \\ The Netherlands: ${ }^{5}$ Department of Epidemiology and Biostatistics, School of Public Health, Imperial College London, \\ London, UK: ${ }^{6}$ Department of Social and Preventive Medicine, Faculty of Medicine, University of Malaya, \\ Kuala Lumpur, Malaysia
}

Submitted 21 October 2016: Final revision received 8 March 2018: Accepted 12 March 2018: First published online 22 April 2018

\begin{abstract}
Objective: In the Netherlands, various FFQs have been administered in large cohort studies, which hampers comparison and pooling of dietary data. The present study aimed to describe the development of a standardized Dutch FFQ, FFQ-NL1.0, and assess its compatibility with existing Dutch FFQs.

Design: Dutch FFQTOOL ${ }^{\mathrm{TM}}$ was used to develop the FFQ-NL1.0 by selecting food items with the largest contributions to total intake and explained variance in intake of energy and thirty-nine nutrients in adults aged 25-69 years from the Dutch National Food Consumption Survey (DNFCS) 2007-2010. Compatibility with the Maastricht-FFQ, Wageningen-FFQ and EPICNL-FFQ was assessed by comparing the number of food items, the covered energy and nutrient intake, and the covered variance in intake.

Results: FFQ-NL1.0 comprised 160 food items, v. 253, 183 and 154 food items for the Maastricht-FFQ, Wageningen-FFQ and EPICNL-FFQ, respectively. FFQ-NL1.0 covered $\geq 85 \%$ of energy and all nutrients reported in the DNFCS. Covered variance in intake ranged from 57 to $99 \%$ for energy and macronutrients, and from 45 to $93 \%$ for micronutrients. Differences between FFQ-NL1.0 and the other FFQs in covered nutrient intake and covered variance in intake were $<5 \%$ for energy and all macronutrients. For micronutrients, differences between FFQ-NL and other FFQs in covered level of intake were $<15 \%$, but differences in covered variance were much larger, the maximum difference being $36 \%$.

Conclusions: The FFQ-NL1.0 was compatible with other FFQs regarding energy and macronutrient intake. However, compatibility for covered variance of intake was limited for some of the micronutrients. If implemented in existing cohorts, it is advised to administer the old and the new FFQ in combination to derive calibration factors.
\end{abstract}

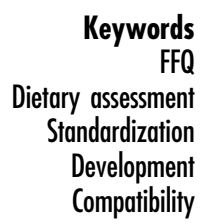

Diet plays an important role in the development of many chronic diseases such as diabetes mellitus ${ }^{(1)}, \mathrm{CVD}^{(2)}$ and cancer $^{(3)}$. In an epidemiological setting, the FFQ is the most widely used method to rank participants according to their habitual dietary intake because it is relatively cheap and easy to administer and process ${ }^{(4)}$, despite potential measurement errors. Dietary habits are complex and tend

\footnotetext{
$\dagger$ Joint last authors.
}

to change over time. Therefore, an up-to-date comprehensive assessment of dietary intake is important. Recent and representative food consumption data have to be used to include those food items in the FFQ that contribute most to the absolute level and variance in intake of energy and nutrients of interest ${ }^{(5)}$. If such an FFQ is applied in various studies on diet-disease relationships in similar types of populations, relative risks can be directly compared and data from populations can be pooled because of the 
standardized dietary assessment ${ }^{(6)}$. Therefore, we decided to develop and validate an up-to-date evidence-based FFQ for the Netherlands, called FFQ-NL1.0, which will allow standardized and comprehensive data collection on the usual intake of a broad range of nutrients and foods in Dutch adults. The development and evaluation of FFQNL1.0 was initiated as part of the so-called BBMRI Rainbow Project, a project aimed at harmonizing the Dutch infrastructure of observational cohort studies, also regarding assessment of nutritional status and dietary intake.

In the Netherlands, large-scale cohort studies have used different FFQs over the past decades ${ }^{(7-12)}$. The availability of the new FFQ-NL1.0 will allow comparable new dietary measurements in ongoing and new cohorts, and therefore stimulate collaboration. For ongoing cohort studies, the question is whether the consecutive dietary measurements, i.e. at baseline with the original FFQ and at followup with the FFQ-NL1.0, can be combined in for example analyses of longitudinal data. Thus, the compatibility of the data collected with the existing FFQs and the new FFQ-NL1.0 is a key issue. To our knowledge, FFQ compatibility has been addressed in only one other study, which focused on food groups only ${ }^{(13)}$.

The empirical validation check of the FFQ-NL1.0 against multiple $24 \mathrm{~h}$ dietary recalls and objective biomarkers as reference methods is described elsewhere ${ }^{(14)}$. In brief, FFQ-NL1.0 estimated intake of energy and macronutrients quite well, compared with repeated $24 \mathrm{~h}$ recalls. However, it underestimated intake of SFA, trans-fatty acids and alcohol, and overestimated intake of most vitamins by $>5 \%$. Median correlation coefficient was 0.39 for energy and macronutrients, 0.30 for micronutrients and 0.30 for food groups. The FFQ underestimated protein intake by an average of $16 \%$, and $\mathrm{K}$ intake by $5 \%$, relative to urinary recovery biomarkers. Correlation coefficients were 0.43-047 between (fatty) fish intake and plasma EPA and DHA, and 0.24-0.43 between fruit and vegetable intake and plasma carotenoids. It was concluded that the validity of the newly developed FFQ-NL1.0 is acceptable to good and that this FFQ seems to be well-suited for future use within Dutch cohort studies among adults.

In the present paper, we describe the development of the FFQ-NL1.0 and its compatibility with a selection of existing FFQs used in previous or ongoing Dutch cohort studies: the Maastricht Study ${ }^{(15)}$; the Wageningen-FFQ, which has been frequently used in dietary controlled intervention studies ${ }^{(9)}$ and in the Leiden Longevity Study ${ }^{(10)}$; and the Dutch cohort of the European Prospective Investigation into Cancer and Nutrition (EPIC) ${ }^{(7,8)}$.

\section{Methods}

\section{Development of FFQ-NL 1.0}

Development of the initial version of the FFQ-NL1.0 took place in the period from April through December 2012. The development of the FFQ-NL1.0 prototype went through several stages and was conducted by a panel of experienced nutrition scientists and research dietitians from three participating centres (Maastricht University, Wageningen University and National Institute for Public Health and the Environment, all in the Netherlands). The main purpose of developing FFQ-NL1.0 was to stimulate identical habitual dietary assessment to be applied in different longitudinal studies.

\section{Selection of nutrients}

First, we identified and selected nutrients and other food constituents that have been associated with chronic disease to be assessed by the new FFQ. These included energy, total protein, vegetable protein, animal protein, total fat, SFA, total trans-fatty acids (TFA), MUFA, PUFA, linoleic acid, $\alpha$-linolenic acid, EPA, DHA, cholesterol, total carbohydrates, mono- and disaccharides, lactose, polysaccharides, dietary fibre, water, alcohol, Ca, Fe (total, haem, non-haem), $\mathrm{K}, \mathrm{Mg}$, retinol, thiamin, riboflavin, vitamin $\mathrm{B}_{6}$, vitamin $\mathrm{B}_{12}$, dietary folate equivalents, vitamin $\mathrm{C}$, vitamin $\mathrm{D}$, vitamin $\mathrm{E}, \beta$-carotene, lutein, zeaxanthin and lycopene.

\section{Identification of informative foods}

Second, we identified informative foods, i.e. foods that contributed most to the total intake or explained most of the variance in intake of energy and the preselected nutrients in a national food consumption survey database $^{(16)}$. For this purpose we used the Dutch FFQTOOL ${ }^{\mathrm{TM}}$, a software toolkit dedicated to the construction, online administration and nutrient calculations of FFQs ${ }^{(17)}$. Details about the development of the Dutch FFQTOOL have been described elsewhere ${ }^{(17)}$. Briefly, the Dutch FFQTOOL uses standard procedures to develop tailor-made FFQs for populations of interest (e.g. specific age and gender groups) as well as for specific foods and nutrients of interest, thereby enabling the assessment of intake of energy and multiple nutrients with sufficient completeness ${ }^{(17)}$.

For the identification of informative foods, we applied the most recent food grouping table present in the Dutch FFQTOOL, which captured five hierarchical levels. Level 1 refers to the main NEVO (NEderlands VOedingsstoffen bestand (Dutch nutrient database)) food product groups ( $n$ 23) with the highest hierarchical level of aggregation. As each of these product groups comprises a large number of food items, these groups are not suitable for being used as a food item in an FFQ. Therefore, within the Dutch FFQTOOL, these twenty-three food groups are further subdivided into four lower (i.e. more detailed) food aggregation levels, including the intermediate levels 2, 3 and 4 which contain foods and food groups available for selection as items for the FFQ (food groups: $n$ 90, $n 242$ and $n 355$, respectively), and level 5 being the lowest level of aggregation, which comprises 2389 food codes as present in the Dutch food composition table ${ }^{(18)}$.

The Dutch FFQTOOL calculated, for each nutrient at each aggregation level: (i) the contribution of a food item 
to total nutrient intake (covered nutrient intake); and (ii) the proportion that a food item contributes to the sum of the variances for all foods within the aggregation level. This measure is used as an approximation for covered variance in nutrient intake.

The calculation of covered nutrient intake and covered variance in nutrient intake was based on two $24 \mathrm{~h}$ telephone dietary recalls, administered on non-consecutive days with an interval of 2 to 6 weeks between 2007 and 2010 in males and females aged 25-69 years ( $n$ 1820) participating in the Dutch National Food Consumption Survey 2007-2010 (DNFCS). The DNFCS was conducted in a nationwide, random population sample of individuals living in separate households ${ }^{(19)}$. Nutrient intake was calculated using an extended version of the NEVO-2011 database $^{(18)}$. At each aggregation level, lists of foods with a cumulative covered nutrient intake and covered variance in nutrient intake of at least $80 \%$ for each nutrient were considered informative foods.

\section{Selection of food items from the informative foods at various aggregation levels}

The third step comprised the selection of the hierarchical level of aggregation of the food items. For example, by selecting more items at the lowest level of aggregation, the items in the FFQ can explain more variance in nutrient intake, but at the same time questionnaire length increases ${ }^{(20)}$. For example, 'Bread' is one of the twenty-three main food groups (aggregation level 1) in the Dutch food composition table (NEVO-table). The nutrient content of the main food product 'Bread' is the weighted average of the nutrient contents of all specific bread products that have been analysed and registered in the NEVO-table under a specific code (NEVO-code; aggregation level 5). In between, intermediate aggregation levels can be distinguished. For instance, 'Bread' at level 1 encompasses 'Bread and bread rolls' (with underlying level 5 NEVOitems) and 'Rusk and crackers' (with underlying level 5 NEVO-items) at level 2. And 'Bread and bread rolls' at level 2 encompass 'Whole bread', 'Wheat bread', 'White bread', 'Raisin bread', 'Croissants' and 'Rye bread' at level 3. 'Rye bread' at level 3 encompasses 'Dark rye bread' and 'Light rye bread' at level 4. And, finally, 'Dark rye bread' contents are the weighted average, i.e. weighting according to consumed amounts, of the nutrient contents of three specific types of dark rye coded in the NEVO-table (level 5). We considered multiple levels of aggregation and multiple nutrients at the same time. Further, to increase face validity, we complemented the list of selected foods with additional foods that were hypothesized to have potential beneficial or detrimental health effects, for example cabbage, different classes of meat (red, lean, processed), fatty and lean fish, sour milk products, soya and other vegetarian products, nuts and grains. These foods were also chosen from the food lists at different aggregate levels in the FFQTOOL. The panel based the selection of food items in such a way that the covered level of intake of all nutrients was $\geq 80 \%$ and covered variance in intake of all nutrients was reasonably high while FFQ-NL1.0 was limited to 160 food items.

To summarize, the expert panel identified firstly relevant, disease-associated nutrients; secondly 'informative' foods, i.e. foods that contribute substantially to the absolute intake and especially the variance in intake of these nutrients (supported by food consumption and food composition data contained by the Dutch FFQTOOL); and thirdly the preferred level of aggregation at which each informative food product should be represented in the FFQ. During this process, all food items were ordered by covered variance from which, top down, the cumulative covered variance was calculated. Those items within the top $80 \%$ range were included as 'informative items'.

\section{Final design characteristics}

As a fourth step, we constructed the semi-quantitative FFQ using the Dutch FFQTOOL. The sequence of food items was determined by following the usual or common daily meal and snacking pattern: breakfast, cold lunch, hot meal, drinks and snacks. Using standard question models, the selected food items were grouped in various questions with sub-questions listed, covering all selected food items either as a grouped main food item or as a subtype (e.g. whole grain bread) of a grouped main food item (e.g. bread). Food item subtypes were presented in increasing order of presumed frequency of use. Consumption of all main food items was assessed by means of a frequency question using an answer model with eleven options, from 'not used' to ' $7 \mathrm{~d}$ /week'. Each of the eighty-two frequency questions was combined with an amount (quantity) question, using an answer model with fourteen standard household servings, from ' $<1$ per day' to ' $>12$ per day'. Depending on the type of food item, additional questions were included, dealing with: (i) subtypes of food items (answer models with eight absolute frequencies, ranging from 'not used' to ' $6-7 \mathrm{~d} /$ week', or five relative frequencies, ranging from 'never' to 'always'); (ii) specification of portion size; (iii) mode of food preparation; and (iv) use of various types of cooking fat. The FFQ covered a 1-year reference period (i.e. the last year).

\section{Pilot testing of FFQ-NL1.O}

The feasibility of the online version of FFQ-NL1.0 was pilot-tested among 188 men and women aged $40-85$ years from the Doetinchem Cohort Study ${ }^{(21)}$. After completing the questionnaire, participants filled out a short evaluation questionnaire about the time needed for completing the questionnaire, problems and obscurities encountered, and foods missed in the FFQ by the participants. Moreover, the respondents rated the user-friendliness and convenience of the FFQ in general and the different types of questions on a scale from 1 ('very poor') to 10 ('extremely good'). With a selection of twenty-eight participants who reported 
the largest number of problems and gave the lowest rates, an in-depth semi-structured evaluation interview was conducted, addressing several general issues such as with respect to reference period, seasonal dependent consumption, clearness of question types (frequency, quantity etc.) as well as the specific difficulties the concerned respondent encountered.

\section{Compatibility of FFQ-NL1.0 with existing FFQs}

We defined compatibility as the degree to which the intake of food groups, food items and nutrients as assessed by FFQ-NL1.0 is the same as those intakes assessed by means of other FFQs with different characteristics.

Selection of existing FFQs for comparison with FFQ-NL1.O We selected semi-quantitative, comprehensive Dutch FFQs with questions regarding the consumption frequency of different food items as well as on portion sizes. Furthermore, the FFQs should have been validated or validation should be ongoing. To capture changes in dietary habits during the past decades, we covered a time window of approximately 25 years in which FFQs were developed and validated. To facilitate qualitative and quantitative comparison with FFQ-NL1.0, we included three FFQs, namely: the FFQ currently used in the Maastricht Study (Maastricht-FFQ, version 2.0 (Maastricht-FFQ2.0)) $^{(15)}$; the Wageningen-FFQ version FQ06 ${ }^{(9,10)}$ which has been used in several studies throughout the Netherlands; and the FFQ used in two Dutch EPIC cohorts (EPIC NL-FFQ) ${ }^{(7,8,22)}$. Supplemental Table 1 (see online supplementary material) shows the nutrients for which each FFQ has been developed and tested for validity.

\section{Compatibility of food items and food groups assessed by} FFQ-NL1.O and existing FFQs

We assessed compatibility of the FFQs by counting the total number of food items within the twenty-three product groups incorporated in the Dutch food composition database (i.e. NEVO classification) ${ }^{(18)}$. To compare food item counts across FFQs, we applied standard definitions and rules for item counting. First, each FFQ-NL1.0 food item should have a unique food composition code. For instance, in the case that the same item occurred more than once in the FFQ, this item was counted once (e.g. whole milk as a drink and whole milk in coffee was counted once). Food item count on grouped food items (e.g. for total fruits or vegetables) differed between FFQs since for some FFQs these items were linked to a unique food composition whereas in other FFQs these items were only included for calibration of intake of foods within the food group. Of note, the unavoidable implication of this approach was that item counts of different FFQs in the present publication may differ slightly from food item counts presented in the original publications of the validation of the concerned FFQs. For example, the discrepancy between the food item count of EPICNL-FFQ performed according to our rules and as reported in its validation paper is explained by the large number of brand names for fats used as bread spreads, which are not counted in the current analyses.

Compatibility of FFQ-NL1.O and existing FFQs regarding nutrient intake

Compatibility of energy and nutrient intake was assessed by comparing the 'covered level of intake' and 'covered variance in intake' by the FFQ-NL1.0, Maastricht-FFQ2.0, Wageningen-FFQ and EPICNL-FFQ. A difference of more than 5\% for energy and macronutrients and 10\% for micronutrients was considered incompatible.

Covered level of intake was calculated as the total estimated intake of each nutrient according to food composition table codes covered by food items included in the FFQ divided by total estimated intake of each nutrient according to food table codes consumed in the appropriate age range of $\mathrm{DNFCS}^{(19)}$.

Covered variance in intake was calculated by assigning the nutrient compositions of the (more aggregated) FFQ food items to the corresponding food table codes of foods reported in the $\operatorname{DNFCS}^{(17)}$. Nutrient values of foods reported in the DNFCS were coded ' 1 ' if they were part of any food item in the concerned FFQ and ' 0 ' if this was not the case. Then, for all persons in the appropriate age range in the DNFCS database, nutrient intake was recalculated using the FFQ food item composition values rather than the original DNFCS food database values. This recalculated nutrient intake was correlated with the originally calculated nutrient intake, and then squared to obtain the proportion covered variance in intake.

To obtain the 'covered level of intake' and 'covered variance in intake' for energy and nutrients in each FFQ, we used the most extensive and appropriate reference food consumption and food composition databases available at the time of the first data collection for each specific FFQ. Table 1 describes the characteristics of the population, structure and development for each FFQ.

\section{Results}

\section{Description and development of FFQ-NL1.O}

The FFQ-NL1.0 included 160 food items. These items were covered by eighty-two main questions with various subquestions. To assess its feasibility, FFQ-NL1.0 was pilot tested in a population of individuals who once were recruited for a cohort study ( $n$ 544). Of the invited cohort members, 212 did not react, 144 refused to participate (no computer, no time, no interest) and 188 (response rate: $34.6 \%)$ completed both the FFQ and a short evaluation questionnaire. The results showed that $46 \%$ of the participants needed on average $45 \mathrm{~min}$ to complete the questionnaire (6\% shorter than $30 \mathrm{~min}, 26 \%$ about $30 \mathrm{~min}, 16 \%$ about $60 \mathrm{~min}, 6 \%$ more than $60 \mathrm{~min}$ ). Only $5 \%$ of participants rated the questionnaire as unsatisfactory $(5$ or less 
on a scale of 1-10). On average, the participants scored the FFQ as 7.9 on a 1-10 scale; as such, FFQ-NL1.0 was not adapted based on results of pilot testing.

\section{Qualitative comparison of FFQ-NL1.0 with existing FFQs}

A comparison of the characteristics of FFQ-NL1.0 with existing Dutch FFQs is presented in Table 1. The FFQNL1.0 had similar characteristics with respect to structure and period of development as the Maastricht-FFQ2.0 but included substantially fewer food items and was designed for slightly younger individuals (25-69 years). The approximate time elapsed since the development of the FFQ-NL1.0 was 0.5 years for the Maastricht-FFQ2.0, 10 years for the Wageningen-FFQ and 20 years for the EPICNL-FFQ. All FFQs used a reference period of the past year, except for the Wageningen-FFQ which used as reference period the previous month. Furthermore, all FFQs estimated consumed amounts by asking for the usually consumed number of units in terms of natural units (e.g. eggs), commercial units (e.g. candy bars, bread slices) or household measures (e.g. cups, serving spoons). Additionally, FFQ-NL1.0, Maastricht-FFQ2.0 and Wageningen-FFQ assessed some consumed amounts in grams (for meat and fish), whereas only the EPICNL-FFQ used photographs to estimate portion sizes of some food items. A particular feature of Wageningen-FFQ and EPICNL-FFQ was the use of open questions on brand names and types of fats used for cooking and for sandwiches.

While the FFQ-NL1.0 included 160 food items, the Maastricht-FFQ2.0, Wageningen-FFQ and EPICNL-FFQ included 253, 183 and 154 food items, respectively. Compared with the other FFQs, the FFQ-NL1.0 had the highest number of food items for 'meat, meat products and poultry', and the lowest item count for 'milk and milk products' and 'cereals and cereal products'. Furthermore,
FFQ-NL1.0 included fewer items on 'dairy', 'fruits', 'vegetables', 'cheese', 'beverages' and 'pastry' compared with the Maastricht-FFQ2.0. The number of food items within other product groups was generally comparable between FFQ-NL and the other FFQs (Table 2). Supplementary Table 2 (see online supplementary material) shows which specific food items are included within each product group for FFQ-NL1.0 and the other FFQs.

\section{Quantitative comparison of FFQ-NL1.0 with existing FFQs}

Table 3 shows covered nutrient intake and covered variance in nutrient intake for energy and the thirty-nine nutrients for which the FFQ-NL1.0 was designed. For the Wageningen-FFQ and the EPICNL-FFQ, the covered level of intake and covered variance in intake were not calculated for those nutrients for which the FFQ was not developed.

For the FFQ-NL1.0, the covered level of intake assessed in the DNFCS 2007-2010 database was $\geq 93 \%$ for energy and macronutrients and $\geq 85 \%$ for micronutrients. The covered nutrient intake for the Maastricht-FFQ2.0, Wageningen-FFQ and EPICNL-FFQ compared with their accompanying DNFCS varied from 94 to $100 \%$ for energy and macronutrients, and from 93 to $100 \%$ for micronutrients, with generally slightly higher values for the Maastricht-FFQ2.0, except for $\alpha$-linolenic acid and linoleic acid. Differences between FFQ-NL1.0 and other FFQs in covered nutrient intake were $<5 \%$ for all macro- and micronutrients, except for covered lycopene intake which was $85 \%$ by FFQ-NL1.0, 100\% for Maastricht-FFQ2.0 and $98 \%$ for Wageningen-FFQ (Table 3 ).

The covered variance in intake from the FFQ-NL1.0 was $\geq 80 \%$ for energy and macronutrients, except for TFA that has a value of $57 \%$. For micronutrients assessed in FFQNL1.0, variations in covered variance were larger and ranged from 45 to $93 \%$. Covered variance in intake of nine

Table 1 Characteristics of the FFQ-NL1.0 and existing Dutch FFQs

\begin{tabular}{|c|c|c|c|c|}
\hline & FFQ-NL1.0 & Maastricht-FFQ2.0 & Wageningen-FFQ & EPICNL-FFQ \\
\hline \multicolumn{5}{|l|}{ Descriptives } \\
\hline Population & General & Diabetes and general & General & General \\
\hline Age & $25-69$ years & $40-75$ years & 19-80 years & 20-70 years \\
\hline \multicolumn{5}{|l|}{ Structure of FFQ } \\
\hline Structured by meal or food groups (yes/no) & Yes & Yes & Yes & Yes \\
\hline Seasonal fruits and vegetables (yes/no) & No & No & Yes & Yes \\
\hline \multicolumn{5}{|l|}{ Portions } \\
\hline Use of potion size questions & Yes & Yes & Yes & Yes \\
\hline Use of photographs & No & No & No & Yes \\
\hline Use of household measures/standard units & Yes & Yes & Yes & Yes \\
\hline Grouped questions & Yes & Yes & Yes & Yes \\
\hline Reference period & Past year & Past year & Past month & Past year \\
\hline \multicolumn{5}{|l|}{ Development } \\
\hline DNFCS & 2007-2010 & 2007-2010 & 1997-1998 & 1987-1988 \\
\hline Food composition table (NEVO) & 2011 & 2011 & 2001, 2006 & 1997-1998 \\
\hline Food items $(n)$ & 160 & 253 & 183 & 154 \\
\hline Validated & Sluik $^{(14)}$ & In progress & Streppel $^{(10)}$, Siebelink $^{(9)}$ & Ocké $(7,8)$ \\
\hline
\end{tabular}

DNFCS, Dutch National Food Consumption Survey. 
Table 2 Number of food items within each food group of the Dutch food composition database (NEVO) for the FFQ-NL1.0 and existing Dutch FFQs

\begin{tabular}{|c|c|c|c|c|}
\hline \multirow[b]{2}{*}{$\begin{array}{l}\text { NEVO food group } \\
\text { classification }\end{array}$} & \multicolumn{4}{|c|}{ Number of food items for each FFQ } \\
\hline & $\begin{array}{l}\text { FFQ- } \\
\text { NL1.0 }\end{array}$ & $\begin{array}{l}\text { Maastricht- } \\
\text { FFQ2.0 }\end{array}$ & $\begin{array}{c}\text { Wageningen- } \\
\text { FFQ }\end{array}$ & $\begin{array}{l}\text { EPICNL- } \\
\text { FFQ }\end{array}$ \\
\hline 1. Bread & 12 & 10 & 13 & 7 \\
\hline Whole grains & 7 & 4 & 8 & 3 \\
\hline Refined grains & 4 & 3 & 5 & 3 \\
\hline Unspecified & 1 & 3 & 0 & 1 \\
\hline $\begin{array}{l}\text { 2. Savoury bread } \\
\text { spreads }\end{array}$ & 1 & 2 & 3 & 1 \\
\hline 3. Cheese & 5 & 9 & 7 & 7 \\
\hline $\begin{array}{l}\text { 4. Milk and milk } \\
\text { products }\end{array}$ & 11 & 41 & 20 & 19 \\
\hline 5. Eggs & 1 & 1 & 1 & 1 \\
\hline $\begin{array}{l}\text { 6. Cereals and } \\
\text { cereal products }\end{array}$ & 3 & 9 & 9 & 5 \\
\hline Whole grains & & 4 & 4 & 2 \\
\hline Refined grains & & 3 & 3 & 1 \\
\hline Unspecified & 3 & 2 & 2 & 2 \\
\hline 7. Soups & 2 & 2 & 2 & 1 \\
\hline 8. Potatoes & 3 & 3 & 3 & 4 \\
\hline 9. Vegetables & 17 & 28 & 12 & 20 \\
\hline 10. Legumes & 1 & 1 & 1 & 1 \\
\hline $\begin{array}{l}\text { 11. Meat, meat } \\
\text { products and } \\
\text { poultry }\end{array}$ & 23 & 16 & 17 & 19 \\
\hline $\begin{array}{l}\text { Red and } \\
\text { processed } \\
\text { meat }\end{array}$ & 21 & 14 & 15 & 16 \\
\hline Poultry & 1 & 1 & 1 & 2 \\
\hline Unspecified & 1 & 1 & 1 & 1 \\
\hline 12. Fish & 8 & 8 & 7 & 3 \\
\hline $\begin{array}{l}\text { 13. Soya and } \\
\text { vegetarian } \\
\text { products }\end{array}$ & 6 & 7 & 6 & 2 \\
\hline 14. Herbs and spices & 0 & 3 & 0 & 1 \\
\hline 15. Mixed dishes & 2 & 7 & 3 & 2 \\
\hline $\begin{array}{l}\text { 16. Fats, oils and } \\
\text { savoury sauces }\end{array}$ & 22 & 23 & 27 & 16 \\
\hline 17. Fruits & 8 & 20 & 7 & 10 \\
\hline $\begin{array}{l}\text { 18. Sugar, sweets and } \\
\text { sweet sauces }\end{array}$ & 9 & 11 & 8 & 6 \\
\hline $\begin{array}{l}\text { 19. Nuts, seeds and } \\
\text { snacks }\end{array}$ & 5 & 9 & 13 & 5 \\
\hline Nuts and seeds & 2 & 1 & 5 & 2 \\
\hline Snacks & 3 & 8 & 8 & 3 \\
\hline $\begin{array}{l}\text { 20. Pastry and } \\
\text { biscuits }\end{array}$ & 4 & 13 & 5 & 5 \\
\hline $\begin{array}{l}\text { 21. Alcoholic and } \\
\text { non-alcoholic } \\
\text { beverages }\end{array}$ & 17 & 28 & 17 & 20 \\
\hline Non-alcoholic & 12 & 20 & 12 & 14 \\
\hline Alcoholic & 5 & 8 & 5 & 6 \\
\hline 22. Clinical formulas & 0 & 1 & 0 & 0 \\
\hline $\begin{array}{l}\text { 23. Miscellaneous } \\
\text { foods }\end{array}$ & 0 & 1 & 2 & 0 \\
\hline Total & 160 & 253 & 183 & 154 \\
\hline
\end{tabular}

out of twenty micronutrients was $\leq 80 \%$, from which lycopene, zeaxanthin, thiamin and vitamin $\mathrm{B}_{6}$ had levels $\leq 70 \%$. Differences between FFQ-NL1.0 and other FFQs in covered variance in nutrient intake were $<5 \%$ for the majority of macronutrients, except for mono- and disaccharides, EPA, TFA and water. Differences were much larger for micronutrients. For the Maastricht-FFQ2.0, covered variance in intake for all micronutrients was $\geq 70 \%$, whereas four out of twelve and two out of eleven micronutrients as assessed by the Wageningen-FFQ and EPICNL-FFQ had values $\leq 70 \%$, respectively.

\section{Additional analyses}

Based on the relatively low covered variance in intake of some B-vitamins and carotenoids, particularly lycopene, the panel performed a new item selection by selecting existing items at a lower level of aggregation to increase covered variance for these nutrients. As a result, a new version of FFQ-NL, FFQ-NL1.1, now includes 169 food items, and consequently covered variance in intake of riboflavin and vitamin $\mathrm{B}_{6}$ considerably improved (Table 3, FFQ-NL1.1). The panel decided not to add an excessive amount of additional items, which would be needed to improve covered variance in intake of carotenoids in general and lycopene in particular.

\section{Discussion}

\section{Principal findings}

The present paper describes the development of a new national FFQ, the FFQ-NL1.0, and its compatibility with three existing FFQs used in different Dutch cohort studies. The four FFQs varied with respect to the number of food items included, question formats, period of development and validation. Compatibility was assessed by comparing the number of food items, the covered energy and nutrient intake, and the covered variance in intake of the FFQNL1.0 relative to existing FFQs. The FFQ-NL1.0 comprised 160 food items, as compared with 253, 183 and 154 food items for the Maastricht-FFQ2.0, Wageningen-FFQ and EPICNL-FFQ, respectively. The items included in the FFQNL1.0 covered $\geq 85 \%$ of intake of energy and all nutrients in the DNFCS. Except for lycopene, the proportion of covered intake was similar compared with the other FFQs. The covered variance in intake ranged from 57 to $99 \%$ for energy and macronutrients, and from 45 to $93 \%$ for micronutrients. Particularly for various micronutrients, covered variance in intake differed from the other FFQs or could not be assessed. Several of these differences were expected because of differences in nutrients for which the various FFQs were developed. The higher covered variance in intake of various nutrients in the MaastrichtFFQ2.0 was expected because of the larger number of included food items.

\section{Development of FFQ-NL1.O}

For the development of FFQ-NL1.0, we used the specially designed software FFQTOOL ${ }^{(23)}$. This tool helps researchers to select informative items to include in an FFQ in a transparent and standardized way, and to design the questionnaire using standardized question and answer formats. For item selection, information on the contribution of food items to total intake and to variance of intake in the DNFCS 
Table 3 Covered nutrient intake and covered variance in nutrient intake (\%) for the FFQ-NL1.0 and existing Dutch FFQs

\begin{tabular}{|c|c|c|c|c|c|c|c|c|c|}
\hline & \multicolumn{4}{|c|}{ Covered nutrient intake } & \multicolumn{5}{|c|}{ Covered variance in nutrient intake } \\
\hline & $\begin{array}{l}\text { FFQ- } \\
\text { NL1.0 }\end{array}$ & $\begin{array}{l}\text { Maastricht- } \\
\text { FFQ2.0 }\end{array}$ & $\begin{array}{c}\text { Wageningen- } \\
\text { FFQ }\end{array}$ & $\begin{array}{l}\text { EPICNL- } \\
\text { FFQ }\end{array}$ & $\begin{array}{l}\text { FFQ- } \\
\text { NL1.0 }\end{array}$ & $\begin{array}{l}\text { FFQ- } \\
\text { NL1.1* }\end{array}$ & $\begin{array}{l}\text { Maastricht- } \\
\text { FFQ2.0 }\end{array}$ & $\begin{array}{c}\text { Wageningen- } \\
\text { FFQ }\end{array}$ & $\begin{array}{c}\text { EPICNL- } \\
\text { FFQ }\end{array}$ \\
\hline Energy & 95 & 98 & 97 & 96 & 95 & 95 & 97 & 95 & 95 \\
\hline \multicolumn{10}{|l|}{ Macronutrients } \\
\hline Total & 97 & 99 & 97 & 97 & 95 & 94 & 96 & 91 & 93 \\
\hline Animal & 98 & 99 & 98 & 98 & 94 & 94 & 96 & 90 & 90 \\
\hline Plant & 95 & 98 & 96 & 95 & 92 & 92 & 94 & 91 & 90 \\
\hline \multicolumn{10}{|l|}{ Carbohydrates } \\
\hline Total & 94 & 98 & 96 & 96 & 91 & 91 & 96 & 93 & 95 \\
\hline Mono/disaccharides & 93 & 98 & 98 & 96 & 88 & 88 & 95 & 93 & 94 \\
\hline Polysaccharides & 94 & 99 & 94 & 96 & 91 & 91 & 94 & 89 & 90 \\
\hline \multicolumn{10}{|l|}{ Fat } \\
\hline Total & 97 & 98 & 97 & 96 & 93 & 93 & 90 & 93 & 88 \\
\hline Saturated & 97 & 99 & 97 & 97 & 89 & 89 & 92 & 92 & 89 \\
\hline Monounsaturated & 97 & 98 & 97 & 96 & 92 & 92 & 88 & 91 & 84 \\
\hline Poly unsaturated & 98 & 97 & 97 & 95 & 89 & 90 & 84 & 93 & 87 \\
\hline C18: $3 n-3$ cis (ALA) & 98 & 96 & 97 & NC & 80 & 82 & 75 & 82 & NC \\
\hline $\mathrm{C} 20: 5 n-3$ cis (EPA) & 98 & 100 & $99 \ddagger$ & NC & 88 & 88 & 90 & $84 \ddagger$ & NC \\
\hline $\mathrm{C} 22: 6 n-3$ cis (DHA) & 98 & 100 & $99 \ddagger$ & NC & 84 & 84 & 88 & $77 \ddagger$ & NC \\
\hline $\mathrm{C} 18: 2$ cis (LA) & 98 & 97 & 98 & NC & 87 & 88 & 82 & $92^{+}$ & NC \\
\hline Trans-fatty acids total & 97 & 99 & 96 & NC & 57 & 57 & 75 & 81 & NC \\
\hline Cholesterol & 97 & 99 & 96 & 97 & 88 & 88 & 94 & 84 & 87 \\
\hline Water & 99 & 100 & 97 & 98 & 99 & 98 & 92 & 95 & 99 \\
\hline Dietary fibre & 94 & 98 & 97 & 95 & 87 & 87 & 97 & 90 & 86 \\
\hline \multirow{2}{*}{\multicolumn{10}{|c|}{ Micronutrients }} \\
\hline & & & & & & & & & \\
\hline $\mathrm{Ca}$ & 97 & 99 & 98 & 97 & 93 & 93 & 96 & 94 & 96 \\
\hline \multicolumn{10}{|l|}{$\mathrm{Fe}$} \\
\hline Total & 96 & 98 & $\mathrm{NC}$ & 95 & 84 & 84 & 81 & $\mathrm{NC}$ & 73 \\
\hline Haem & 99 & 99 & NC & NC & 87 & 87 & 90 & NC & NC \\
\hline Non-haem & 95 & 98 & NC & NC & 82 & 82 & 78 & NC & $\mathrm{NC}$ \\
\hline $\mathrm{Mg}$ & 96 & 98 & NC & $97 \ddagger$ & 89 & 89 & 91 & NC & $90 \ddagger$ \\
\hline $\mathrm{K}$ & 97 & 98 & NC & $\mathrm{NC}$ & 93 & 90 & 94 & NC & $\mathrm{NC}$ \\
\hline$\beta$-Carotene & $96 \ddagger$ & $99 \ddagger$ & 96 & $93 \ddagger$ & $84 \ddagger$ & $84 \ddagger$ & $86 \ddagger$ & 16 & $60 \ddagger$ \\
\hline Folate equivalents & $97^{+}$ & 98 & 98 & $\mathrm{NC}$ & $73^{+}$ & $74^{+}$ & $71^{+}$ & 78 & $\mathrm{NC}^{+}$ \\
\hline Retinol† & 98 & 98 & 98 & $95 \ddagger$ & 89 & 89 & 76 & 94 & $85 \ddagger$ \\
\hline Thiamin & 95 & 98 & 96 & $95^{+}$ & 60 & 61 & 72 & 23 & 78 \\
\hline Riboflavin & 97 & 99 & 97 & 97 & 67 & 75 & 84 & 89 & 88 \\
\hline Vitamin $B_{6}$ & 98 & 98 & 97 & 96 & 55 & 72 & 79 & 84 & 85 \\
\hline Vitamin $\mathrm{B}_{12}$ & 98 & 99 & 98 & $99 \ddagger$ & 80 & 80 & 75 & 89 & $30 \ddagger$ \\
\hline Vitamin C & 97 & 99 & 97 & 94 & 82 & 83 & 89 & 62 & 89 \\
\hline Vitamin D & 98 & 97 & 97 & NC & 74 & 74 & 76 & 84 & NC \\
\hline Vitamin $E$ total & 97 & 97 & 99 & $95 \ddagger$ & 77 & 79 & 77 & 90 & $89 \ddagger$ \\
\hline Lactose & $94 \ddagger$ & $97 \ddagger$ & NC & $\mathrm{NC}$ & $89 \ddagger$ & $89 \ddagger$ & $97 \ddagger$ & NC & $\mathrm{NC}$ \\
\hline Lycopene & $85 \ddagger$ & $100 \ddagger$ & 98 & NC & $45 \ddagger$ & $45 \ddagger$ & $81 \ddagger$ & 63 & NC \\
\hline Lutein & $98 \ddagger$ & $99 \ddagger$ & NC & NC & $70 \ddagger$ & $71 \ddagger$ & $72 \ddagger$ & $\mathrm{NC}$ & $\mathrm{NC}$ \\
\hline Zeaxanthin & $99 \ddagger$ & $100 \ddagger$ & NC & NC & $60 \ddagger$ & $60 \ddagger$ & $74 \ddagger$ & NC & NC \\
\hline
\end{tabular}

ALA, a-linolenic acid; LA, linoleic acid; NC, not calculated (as FFQ was not developed for these nutrients).

${ }^{*} \mathrm{New}$ results after selection of items at a lower level of aggregation to improve covered variance for thiamin, riboflavin, vitamin $\mathrm{B}_{6}$, lycopene and zeaxanthin. tFor EPICNL-FFQ, the numbers for retinol reflect the sum of retinol equivalents and carotenoids.

¥Coverage of nutrient $<70 \%$ in in food composition database NEVO 2011 (used for FFQ-NL1.0 and Maastricht-FFQ2.0), NEVO 2001 (Wageningen-FFQ) and NEVO 1998 (EPICNL-FFQ).

is used ${ }^{(17)}$. The DNFCS population is representative for the population in the Netherlands with respect to age, education, region of residence and population density.

A key issue during the development of FFQ-NL1.0 was the selection of food items that would explain as much total variance in each specific nutrient intake as possible, but at least $80 \%$. A limitation of the FFQTOOL is that it cannot perform the optimal selection of food items across the different levels of food item aggregation. In the current study, this part of item selection was performed by the panel. When deciding on the level of aggregation, the panel had to decide on the right balance between the maximum explained variance and the number of items included in the food list. For some nutrients, particularly B-vitamins and carotenoids, this resulted in a rather low explained variance. This may be explained by the rather poor coverage rate of these nutrients by the food items in the Dutch food consumption table (NEVO-table). As such, the panel made a new item selection for an updated version of the FFQ (FFQ-NL1.1) by selecting some items relevant for these nutrients at a lower level of aggregation. This slightly improved the covered 
variance of vitamin $\mathrm{B}_{6}$ intake only. For other nutrients, improvement in the covered variance would require inclusion of many more food items, similar to the Maastricht-FFQ2.0. This was not implemented. The rather low covered variance in TFA may be compromised by substantial changes in TFA contents of food products over time as a consequence of food production regulation and policies.

\section{Backward compatibility of FFQs}

To the best of our knowledge, the present study is the first to assess the compatibility of food and nutrient intake for an FFQ with other FFQs within one country. Compatibility is especially relevant if the FFQ-NL1.0 is used for follow-up dietary assessment in ongoing cohort studies that collected baseline dietary information using another FFQ. One recent study focused on the compatibility of habitual intake of food products (grams per day) of two dietary FFQs as applied in the Danish National Birth Cohort (DNBC) and the Norwegian Mother and Child Cohort Study $(\mathrm{MoBa})^{(13)}$. The FFQs used in these two cohort studies were comparable with respect to time window of usage, procedures to calculate intake, questions to calibrate intakes of different food groups, and the majority of questions were similar ${ }^{(13)}$. The current study did not assess compatibility by means of comparing habitual intake of food items, as was done before $^{(13)}$. Such direct comparison of habitual intake from FFQ-NL1.0 and the other FFQs is hampered because the FFQs differed with respect to the period of usage and validation, the number of food items included and the purpose of the cohort study they were designed for. Nevertheless, the current study focused on comparison of (the number of) food items within twenty-three main food groups and theoretical compatibility of nutrient intake as assessed by the FFQs. For the latter, the percentage of covered nutrient intake and percentage of covered variance in nutrient intake by the food items in each FFQ were assessed in the DNFCS most close to the period the FFQ was applied in its cohort study. A more thorough evaluation of the mutual compatibility of various FFQs - with the focus on the new FFQNL1.1 - might have been pursued by, for instance, administering each of these FFQs simultaneously in the same study population, in the meantime accounting for learning effects of repeated FFQ assessment. Within the context of the current project such a survey approach to elucidate compatibility was unfeasible. Nevertheless, if the same FFQ is applied in similar populations, it will give rise to the same over- or underestimation of food and nutrient intake, and if assessment errors are non-differential, associations can be compared and pooled.

Several limitations of our study must be mentioned. First, we included only three Dutch FFQs used in large cohorts. For feasibility reasons we selected three previously validated FFQs with comparable structures regarding meal patterns, questions on portion sizes and grouped questions. Second, in our evaluation of compatibility, relevant aspects such as differences in reference period, question formulation, answer models and portion size assessment ${ }^{(24)}$ were not considered or only described qualitatively. Third, the evaluation of FFQs for covered intake level and covered variance was performed for the time period in which the FFQs had been administered. As a consequence, national food consumption databases for different periods were used which differed with regard to methodology (e.g. two consecutive day food records $v$. two non-consecutive $24 \mathrm{~h}$ dietary recalls) and completeness of the food composition database $^{(16,25)}$. Furthermore, food composition of not all food items was estimated for the Wageningen-FFQ and the EPICNL-FFQ. For this reason, compatibility of FFQ-NL1.0 with the Wageningen-FFQ and the EPICNL-FFQ could not be assessed for various carotenoids, vitamins and fatty acids.

\section{Conclusion and relevance}

Covered energy and nutrient intake level of a predefined list of energy, macronutrients and many micronutrients of a newly developed Dutch national FFQ, the FFQ-NL1.0, are compatible with those from three existing Dutch FFQs. However, compatibility for covered variance of intake was limited for some of the vitamins and carotenoids. The FFQ-NL1.1 is available from 2018 onwards for use in future studies in Dutch adults. If implemented in existing cohorts it is advised to administer the old and the new FFQ in combination to derive calibration factors. FFQ-NL1.1 will stimulate standardized and comparable assessment of dietary intake in future dietary studies in the Netherlands and will facilitate comparison and pooled analyses with previous and new cohort studies on the associations between dietary intake and chronic diseases.

\section{Acknowledgements}

Financial support: This research was financially supported by BBMRI-NL, a Dutch hub within the European Biobanking and Biomolecular Resources Research Infrastructure, financed by the Dutch Government (grant number NWO 184.021.007). The funder had no role in the design, analysis or writing of this article. Conflict of interest: None. Authorship: M.C.O., P.C.D., M.C.J.M.v.D. and E.J.M.F. designed the study. S.J.P.M.E., M.C.J.M.v.D., M.C.O. and S.M. carried out the analysis and interpreted the data. S.J.P.M.E. drafted the manuscript. All authors interpreted the data, critically reviewed the article for important intellectual content and gave final approval of the version to be published. Ethics of buman subject participation: Not applicable.

\section{Supplementary material}

To view supplementary material for this article, please visit https://doi.org/10.1017/S1368980018000885 


\section{References}

1. Knowler WC, Barrett-Connor E, Fowler SE et al. (2002) Reduction in the incidence of type 2 diabetes with lifestyle intervention or metformin. N Engl J Med 346, 393-403.

2. Stampfer MJ, Hu FB, Manson JE et al. (2000) Primary prevention of coronary heart disease in women through diet and lifestyle. $N$ Engl J Med 343, 16-22.

3. Wiseman M (2008) The second World Cancer Research Fund/American Institute for Cancer Research expert report. Food, nutrition, physical activity, and the prevention of cancer: a global perspective. Proc Nutr Soc 67, 253-256.

4. Jacques PF, Sulsky SI, Sadowski JA et al. (1993) Comparison of micronutrient intake measured by a dietary questionnaire and biochemical indicators of micronutrient status. $\mathrm{Am} \mathrm{J}$ Clin Nutr 57, 182-189.

5. Block G, Hartman AM, Dresser CM et al. (1986) A databased approach to diet questionnaire design and testing. Am J Epidemiol 124, 453-469.

6. Merritt MA, Tzoulaki I, van den Brandt PA et al. (2016) Nutrient-wide association study of 57 foods/nutrients and epithelial ovarian cancer in the European Prospective Investigation into Cancer and Nutrition study and the Netherlands Cohort Study. Am J Clin Nutr 103, 161-167.

7. Ocke MC, Bueno-de-Mesquita HB, Goddijn HE et al. (1997) The Dutch EPIC food frequency questionnaire. I. Description of the questionnaire, and relative validity and reproducibility for food groups. Int J Epidemiol 26, Suppl. 1, S37-S48.

8. Ocke MC, Bueno-de-Mesquita HB, Pols MA et al. (1997) The Dutch EPIC food frequency questionnaire. II. Relative validity and reproducibility for nutrients. Int J Epidemiol 26, Suppl. 1, S49-S58.

9. Siebelink E, Geelen A \& de Vries JH (2011) Self-reported energy intake by FFQ compared with actual energy intake to maintain body weight in 516 adults. Br J Nutr 106, 274-281.

10. Streppel MT, de Vries JH, Meijboom S et al. (2013) Relative validity of the food frequency questionnaire used to assess dietary intake in the Leiden Longevity Study. Nutr J 12, 75.

11. Goldbohm RA, van den Brandt PA, Brants HA et al. (1994) Validation of a dietary questionnaire used in a large-scale prospective cohort study on diet and cancer. Eur J Clin Nutr 48, 253-265.

12. Goldbohm RA, van 't Veer P, van den Brandt PA et al. (1995) Reproducibility of a food frequency questionnaire and stability of dietary habits determined from five annually repeated measurements. Eur J Clin Nutr 49, 420-429.
13. Olsen SF, Birgisdottir BE, Halldorsson TI et al. (2014) Possibilities and considerations when merging dietary data from the world's two largest pregnancy cohorts: the Danish National Birth Cohort and the Norwegian Mother and Child Cohort Study. Acta Obstet Gynecol Scand 93, 1131-1140.

14. Sluik D, Geelen A, de Vries JH et al. (2016) A national FFQ for the Netherlands (the FFQ-NL 1.0): validation of a comprehensive FFQ for adults. Br J Nutr 116, 913-923.

15. Schram MT, Sep SJ, van der Kallen CJ et al. (2014) The Maastricht Study: an extensive phenotyping study on determinants of type 2 diabetes, its complications and its comorbidities. Eur J Epidemiol 29, 439-451.

16. Ocké MC, Hulshof K, Bakker M et al. (2006) Naar een nieuw Nederlands voedingspeilingsysteem (Towards a new system of dietary monitoring in the Netherlands). http://www. rivm.openrepository.com/rivm/handle/10029/7344 (accessed September 2016).

17. Molag ML, de Vries JH, Duif N et al. (2010) Selecting informative food items for compiling food-frequency questionnaires: comparison of procedures. Br J Nutr 104, 446-456.

18. National Institute for Public Health and the Environment (2011) NEVO online version 2011/3.O. Bilthoven: RIVM; available at http://www.rivm.nl/nevo_en/online/

19. van Rossum CT, Fransen HP, Verkaik-Kloosterman J et al. (2011) Dutch National Food Consumption Survey 2007-2010. Bilthoven: RIVM.

20. Gerdessen JC, Souverein OW, van 't Veer P et al. (2015) Optimising the selection of food items for FFQs using Mixed Integer Linear Programming. Public Health Nutr 18, 68-74.

21. Verschuren WM, Blokstra A, Picavet HS et al. (2008) Cohort profile: the Doetinchem Cohort Study. Int J Epidemiol 37, 1236-1241.

22. Beulens JW, Monninkhof EM, Verschuren WM et al. (2010) Cohort profile: the EPIC-NL study. Int J Epidemiol 39, $1170-1178$.

23. Molag ML (2010) Towards Transparent Development of Food Frequency Questionnaires. Scientific Basis of the Dutch FFQ-Tool: A Computer System to Generate, Apply and Process FFQs. Wageningen: Wageningen University.

24. Thompson FE, Subar AF, Brown CC et al. (2002) Cognitive research enhances accuracy of food frequency questionnaire reports: results of an experimental validation study. J Am Diet Assoc 102, 212-225.

25. Ocké M, Hulshof K \& Van Rossum C (2005) The Dutch national food consumption survey 2003. Methodological issues. Arch Public Health 63, 227-241. 